\title{
Exploring nurse preceptors' perceptions of benefits and support of and commitment to the preceptor role in the Western Cape Province
}

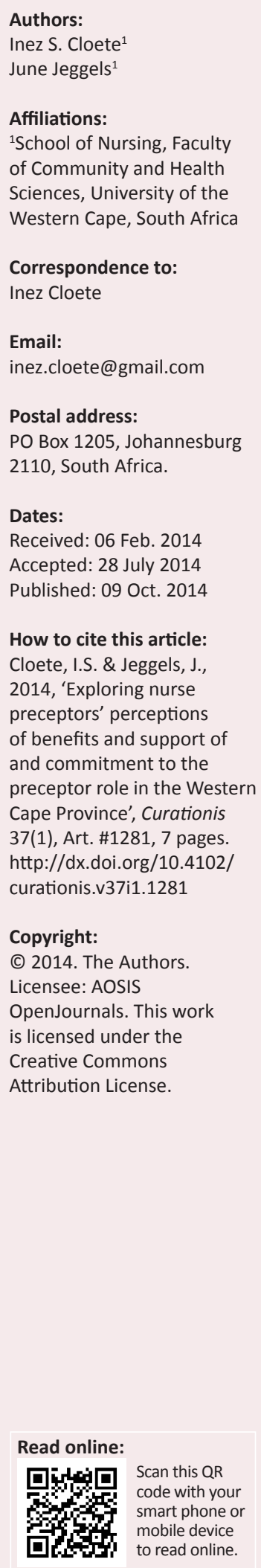

Background: A preceptor is a specialised tutor who provides practical training to students in the practice setting. They are frequently used to orientate nursing students to prepare them for their duties as professional nurses. In the Western Cape Province professional nurses attend a training programme to prepare them for the role of preceptor. After completion of the training it is unclear how the trained nurse preceptors perceive their preparation for the role. The perceptions of preceptors may influence their commitment to their role.

Objective: The purpose of this study was to explore nurse preceptors' perceptions of benefits, support and commitment to the preceptor role. A conceptual framework guided the study which replicated previous studies that explored nurse preceptors' perceptions.

Method: A quantitative approach utilising a descriptive correlational design was used in this study to address the research questions. A convenience sample was drawn from preceptors $(n=60)$ who had completed a preceptor training programme at the University of the Western Cape. Instrumentation for the study included the following scales: preceptors' perceptions of benefits and rewards, preceptors' perceptions of support, and commitment to the preceptor role. Data analysis was performed using SPSS 20.0.

Results: The findings indicate that nurse preceptors were committed to their role.

Conclusion: The findings of this study are supported by Kanter's model of structural determinants of behaviour in organisations, since preceptors who see themselves as having access to opportunity and support are likely to be committed to their role.

\section{Introduction and background}

The education of professional nurses takes place at universities and colleges. Nurse education consists of a theoretical and a practical training component, which prepares nursing students for their duties as professional nurses. The South African Nursing Council (SANC) is the professional body that regulates nurse training in South Africa (SANC Nursing Act No. 33 of 2005). SANC Regulation 425 of February 1985 as amended (SANC 1985) relates to approval of the nursing curriculum of higher education institutions offering nursing education and training programmes, and specifies minimum requirements for the education and training of a nurse over a four-year degree or diploma course.

The practical component of nursing education includes development of the student nurse's clinical skills. These skills are acquired in both a simulated and a real clinical service setting, such as hospitals and clinics. In the real setting nursing students require supervision. The higher education institution employs clinical supervisors who have direct contact with students for half an hour per student per week. For the rest of the placement period students are supervised by the professional nurses in the clinical setting. These professional nurses do not all necessarily have a nursing education qualification. The need to strengthen the clinical teaching skills of professional nurses was identified by the Director of Nursing in the Western Cape Province (Mabuda, Potgieter \& Alberts 2008:19). In order to strengthen professional nurses' clinical teaching expertise, the University of the Western Cape (UWC) is offering preceptorship training, which is a continuing education course for professional nurses.

A preceptor is defined as a specialised tutor who gives practical training to the student in the practice setting (Moyer \& Wittmann-Price 2008:272). Preceptors facilitate the development of knowledge, clinical skills and professional attributes in nursing (Smedley 2008:185). Nurse preceptors encourage the enhancement of critical thinking and problem-solving skills that are trademarks of an academic education (Carlson, Wann-Hansson \& Pilhammar 2009:526). Nurse preceptors play an essential role in the transition of nursing students from the classroom to 
clinical practice (Staykova, Huson \& Pennington 2013:32). Preceptorship refers to the relationship between the preceptor and the student, is regarded as a practice education model in nursing and serves as a viable alternative clinical teaching strategy (Franklin 2013:37).

Benefits and rewards are positive outcomes associated with services (Dibert \& Goldenberg 1995: 1144). For the purpose of this study benefits and rewards relate to positive outcomes associated with the preceptor role.

In this study support refers to the conditions that enable the performance of a function related to the preceptor role. The perceptions of preceptors are related to the conditions that enable the performance of their preceptor functions, such as access to resources, information and supplies, in addition to the ability to meet organisational goals when these resources are mobilised (Dibert \& Goldenberg 1995:1149). Commitment refers to a combination of attitudes that reflect one's dedication to a role (Dibert \& Goldenberg 1995:1149). For the purpose of this study commitment refers to a combination of attitudes that preceptors reflect in their dedication to the preceptor role.

The preparation of and support for professional nurses to become preceptors is important in the delivery of effective, high-quality clinical learning experiences that meet nursing students' learning needs or outcomes. Adequate preceptor preparation is suggested, including preceptor orientation programmes, formal preceptor education, and time to complete initial and continuing preceptor education to remain committed to the preceptor role (Kaviani \& Stillwell 2000:218; Myrick \& Yonge 2004:378; Scott 2010:199).

\section{Problem statement}

Nurse preceptors play an important role in clinical teaching and learning. Preceptors are prepared through various training programmes, including workshops ranging in duration from 1 day to 3 days to 2 weeks, whilst other training programmes are provided within a period of 6-12 months and include formal training, preparation and continuing support (Raines 2012:76; Currie \& Watts 2012:4). After the professional nurses have successfully completed the preceptorship training programme they return to the clinical facilities. However, it is unclear whether they are committed to the role or whether they perceive benefits and support for the role. Findings of this study will add to what is known about preceptors' perceptions and may help guide evaluation of the preceptorship training programme offered by UWC. The results may also inform nursing managers about the perceived benefits and rewards and the support needed by preceptors, and add to the body of knowledge about clinical teaching and learning.

\section{Research objectives}

The objective of the research was to explore and describe nurse preceptors' perceptions of benefits, support and commitment to the preceptor role.

\section{Literature review}

The bulk of the literature accessed in relation to this topic concerned international studies. Very little has been published in South Africa on the perceptions of nurse preceptors of the benefits, support and commitment to the preceptor role. The literature review was limited to the most appropriate aspects relating to this study.

\section{Benefits and rewards of the preceptorship role}

Zilembo and Monterosso (2008:89) completed a quantitative study in Australia that focused on interactions that take place within and around the multifaceted student and/ or preceptor relationship. Their study identified increasing one's own knowledge base and the satisfaction of teaching as rewards of preceptoring.

Moran (2011:1) conducted a quantitative study in the midwestern part of the United States of America (USA), which included a sample of 674 professional nurses and used questionnaires as data collection tools. That study concluded that benefits of the preceptorship role include sharing knowledge with new nurses and nursing students, assisting new staff and nursing students to integrate into the nursing unit, contributing to their profession, and gaining personal satisfaction from the role.

A 'love' of teaching and wanting to facilitate the development of the next generation incentivises some nurses to accept the role of preceptor (Yonge et al. 2008:1). Other nurses reported benefits such as 'passing the torch' to the next generation of providers, sharing knowledge and expertise, coaching others, demonstrating expertise to the patients, providing networking opportunities, and receiving credit for continuing education (Campbell \& Hawkins 2007:1).

Campbell and Hawkins (2007:24) stated that rewards can be given to preceptors as a way of thanking them for their service to the school. Some examples of rewards include tuition for courses or continuing education, access to the university's online services, and access to the university library system (Campbell \& Hawkins 2007:24; Yonge et al. 2008:114).

A study amongst 82 preceptors in the USA by Hyrkäs and Shoemaker (2007:521) found that the benefits and rewards of preceptorship included the following: teaching new student nurses $(n=82)$; improvement of teaching skills $(n=81)$; gaining personal satisfaction from the role $(n=82)$; and being recognised as a role model $(n=82)$.

\section{Perceptions of support for the preceptorship role}

According to a study in Ireland by McCarthy and Murphy (2010:234), the majority of preceptors found the role stressful and burdensome, and did not feel adequately supported by their clinical managers. The perceived levels of stress that most respondents $(83 \%)$ reported in relation to their preceptor role were mild or moderate in severity. Only seven respondents $(11 \%)$ reported experiencing no stress. 
Preceptors expressed the need for protected time, support, feedback and recognition from management for undertaking this role. One-third (33.5\%) of the participants agreed that they feel supported by hospital management staff, whilst $38 \%$ disagreed, $23.6 \%$ were undecided and $4.2 \%$ did not answer the question.

Hautala, Saylor and O'Leary-Kelley (2007:64) completed a study using a convenience sample of 65 registered nurses (preceptors) in the San Francisco Bay area of the USA. The study focused on the perceptions of preceptors in relation to support in their working environment. Many preceptors felt adequately supported (88\%), of whom 83\% felt confident in their role even though it meant an increase in workload. However, moderate to above moderate levels of stress were reported because of the high workload and limited organisational support. Many preceptors (88\%) believed they were adequately prepared for the role, $88 \%$ felt that management was committed to the programme and $91 \%$ felt that co-workers supported the programme. Most respondents also perceived that educators, managers, clinical nurse specialists and co-workers were committed to the success of the programme.

Bradshaw et al. (2011) conducted a two-phase study in Ireland using a mixed-method approach that included focus groups and a survey. The total population of preceptors $(n=837)$ in the mid-west region of Ireland participated in the study. This included 536 general nurses, 177 mental health nurses and 124 intellectual disability nurses, who were accessed using up-to-date lists of all preceptors in the clinical placement facilities. Over half of the preceptors (57\%) perceived that the preparation they had received was sufficient in supporting their preceptor role, $40 \%$ believed it was minimal and 3\% felt it was excessive. The most frequently used sources of support were communication with other preceptors $(56.7 \%)$, referring to competency assessment guidelines (56.7\%), and consulting material from a preceptorship training course (29.4\%).

\section{Perceptions of commitment to the preceptorship role}

In extending what is known about preceptorship, Hallin and Danielson (2008:161) state on the basis of research in Sweden that factors influencing preceptors' commitment to the role include self-awareness, self-confidence, age, experience, and attending a preceptor training course. These attributes, and an interest in precepting, therefore influence registered nurses' commitment to the preceptorship role.

A quantitative study in Ontario, Canada, used a convenience sample of 59 preceptors, of whom $90 \%$ had attended a preceptor training programme during the preceding decade. Findings were that the preceptors tend to be committed to their role when worthy benefits, rewards and support are present. The most highly regarded benefits and rewards included integrating preceptees into the nursing staff, sharing knowledge and skills with preceptees, teaching nursing students, and personal satisfaction (Brown 2010:61).
Dube (2009:1) completed a quantitative study in Botswana to explore the views of preceptors and preceptees regarding role fulfilment in clinical practice settings. Most (91.4\%) of the 55 preceptors indicated that they had an interest in teaching nursing students, whilst $8.6 \%$ did not show any interest. The claim could thus be made that commitment to the preceptor role is influenced by the professional nurse showing an interest in the teaching of nursing students.

\section{Conceptual framework}

Kanter's (1977) model of structural determinants of behaviour in organisations was used in this study. The underlying concepts of an integrated structural model of human behaviour in organisations are opportunity and power. According to Kanter (1977), if preceptors have access to power (information, support, resources, ability to mobilise) and opportunity (the chance to increase competence and skills, advancement, recognition of skills and rewards) they may increase their commitment to the preceptor role. If preceptors perceive that nurse managers or educators do not support their decisions or if they lack sufficient time and/or training to adequately perform their role, they will be less likely to continue in the role of preceptor. If rewards for the role of preceptorship are not forthcoming, preceptors' commitment to the role tends to decrease (Dibert \& Goldenberg 1995:1149; Brown 2010:61).

\section{Research method and design Design}

A descriptive correlational design was used for this study to determine correlation of interrelationships between variables pertaining to preceptors' perceptions. These variables referred to the benefits and rewards, the perceptions of support, and the perceptions of commitment to the preceptor role.

The researcher wanted to determine descriptive statistics to elaborate on the different variables. Inferential statistics were determined to identify the relationships amongst the variables. Descriptive statistics refers to the data described in the study, whereas inferential statistics refers to the conclusions made therefrom (Tullis \& Albert 2008:24). In this study data were gathered according to a specific plan, using formal instruments.

\section{Population and sampling}

The study population included 60 professional nurses who registered for the nurse preceptor training programme at UWC's School of Nursing between January 2010 and March 2012. Inclusion criterion for this study were trained preceptors who are employed by the provincial government of the Western Cape. Trained preceptors who are employed by higher education institutions or situated outside the Western Cape were excluded.

A convenience sampling method was used to involve and draw participants from the population. This sampling 
method was used because it allowed the researcher to obtain basic data and trends regarding the study and gave the researcher a choice to select readily available individuals for the study (Brink, Van der Walt \& Van Rensburg 2006:132). Of the 60 trained preceptors, two could not be traced, four formed part of the exclusion criteria, two were excluded because they formed part of the pretesting, six refused to participate, and five indicated that they had not successfully completed the training. This left the researcher with 41 individuals for the research study.

\section{Instrument and data collection}

The data collection tool used to explore the professional nurses' perceptions was based on a questionnaire developed by Dibert and Goldenberg (1995:1150). The researcher selected those questions from this previously tested questionnaire which were most appropriate for this study. The four-part questionnaire was adapted to specifically address the study question. Section 1 of the questionnaire dealt with the participants' demographic data, whilst sections 2 to 4 were based on the preceptors' perceptions of benefits and rewards (PPBR), preceptors' perceptions of support (PPS), and commitment to the preceptor role (CPR) (Dibert \& Goldenberg 1995:1144). Questions posed in these three sections were closed and included a Likert scale. Each participant filled in the questionnaire individually.

\section{Pretesting of the instrument}

The questionnaire was pretested using two preceptors who had completed the preceptorship training programme. This tested validity and reliability by establishing whether the questions in the questionnaire were unambiguous and comprehensible. In addition, pretesting should mirror the conditions of the final survey and could lead to changes in the design of the research questionnaire (Supino \& Borer 2012:171). Pretesting of the instrument revealed that the questions were clear and no adaptions had to be made. The participants used in the pretesting were excluded from the main study.

\section{Data analysis}

The Likert scale scoring ranged from 1 to 6 , with $1=$ Strongly disagree, 2 = Moderately disagree, 3 = Disagree, 4 = Agree, $5=$ Moderately agree, and $6=$ Strongly agree. The data were analysed using the Statistical Package for Social Sciences (SPSS) 20.0 software. Data were analysed and presented in table form reflecting frequencies, means and standard deviations (SDs).

Descriptive statistics were used to analyse the data collected from the social demographic questionnaire and inferential statistics were used to analyse the remaining data. Spearman's correlation coefficients were used to assess the correlation between variables of the PPBR, CPR and PPS scales, since these variables were measured at the interval level.
Analyses of relationships amongst specific demographic variables (highest education level, years of experience as a professional nurse and area of current employment) and scores on CPR were done using non-parametric tests (including the Mann-Whitney $U$ test). A significance level of 0.05 (two-tailed) was selected for interpreting the results. Items that measured the benefits and rewards, support and commitment were ranked according to means, from highest to lowest, to establish those most preferred by the preceptors.

\section{Results and discussion \\ Section A: Demographic data}

Most of the preceptors $(65.9 \%$ or $n=27)$ were employed in the clinical unit. The non-parametric Mann-Whitney test was used to determine correlation between area of current employment and CPR. This study indicated that there was a significant difference in mean CPR between those in clinical units and those in education units $(p=0.018)$. Only 40 participants' responses for current area of employment were considered for this test, since one participant indicated working in a district unit. Results show that preceptors working in clinical units are more committed to their role than those working in education units. This could be due to increased exposure to preceptorship in the clinical units.

\section{Section B: Nurse preceptor's perceptions of benefits and rewards of the preceptor role}

The trained preceptors' perceptions of benefits and rewards are presented in Table 1.

Only five (12.2\%) participants perceived no gain in personal satisfaction from the role. The researcher correlated these data with the demographic data, and found that these participants had an average of less than six months' preceptorship exposure. The short duration of preceptorship exposure may be clinically significant, as it could be the reason for their not having gained any personal satisfaction. The one participant who strongly disagreed that personal satisfaction was gained, indicated that she was a quality assurance manager and was not working in either a clinical or an education unit. This participant was thus not using her preceptor skills and therefore not gaining any personal satisfaction from this role, which could account for her strong disagreement. This result relates to Kanter's (1977) model; if benefits and rewards are insufficient, it is less likely that nurse preceptors will be committed to the preceptor role.

TABLE 1: Highest rank-ordered mean scores for the preceptors' perceptions of the benefits and rewards: Means and SDs.

\begin{tabular}{llll}
\hline Item & $\boldsymbol{N}$ & $\boldsymbol{M}$ & $\mathrm{SD}$ \\
\hline Teach nursing students to the best of my ability & 41 & 5.83 & 0.495 \\
Improve my teaching skills & 41 & 5.24 & 1.067 \\
Be recognised as a role model & 41 & 4.95 & 1.024 \\
Gain personal satisfaction & 41 & 4.71 & 1.521 \\
\hline$N, 41$ (number of participants); $M$, mean (the average between 1 and 6); SD, standard \\
deviation.
\end{tabular}


In Dibert and Goldenberg's study (1995:1148) the mean scale of preceptors gaining personal satisfaction from the preceptor role was 4.93 amongst a total of 59 participants. In this study the mean scale was 4.71 with a total of 41 participants responding to this question. These results are similar and indicate that the nurse preceptors are gaining personal satisfaction from this role. In the studies by Baltimore (2004:133) and Kupferman (2005:56) preceptors report feelings of great personal satisfaction, self-enrichment and energy as a result of participating in the education of future professional nurses.

There is no indication that the perceived benefits and rewards of the preceptor role impact on the level of commitment which the preceptors have to their role. Positive responses to the questions related to gaining personal satisfaction and being recognised as a role model, which suggests that clinical significance may influence the participants' commitment to the preceptor role. Usher et al. (1999: 510) found statistically significant correlations ( $r=0.54, p=0.001, n=98)$ between benefits and rewards, and commitment, which means that as long as there were perceived benefits and rewards, the preceptors were committed to their role.

\section{Section C: Nurse preceptors' perceptions of support for the preceptor role}

The trained PPS for the role are presented in Table 2.

Although most participants $(63.4 \%$ or $n=26)$ in this study felt comfortable with the workload, nevertheless just over one-third $(36.6 \%$ or $n=15)$ felt that the workload was inappropriate when functioning as a nurse preceptor, resulting in a mean of 3.93. This is slightly lower than the mean of 4.13 found in Dibert and Goldenberg's (1995) study amongst 55 participants (1995:1149). It is therefore evident that on average the preceptors perceive the workload as appropriate when functioning as a nurse preceptor.

Preceptors' perceptions of the perceived support did not relate to their CPR. Although no statistical significance was found $(p=0.125)$ between PPS and CPR, the perceived support from nurse managers and professional nurses could influence the preceptors' commitment to the role. This relates to Kanter's (1977) model; if preceptors have access to support they may have an increase in CPR. However, Hyrkäs and Shoemaker (2007:522) did find a statistically significant correlation between perceptions of support and commitment to the role $(p=0.01)$, emphasising the need for efficient support structures for nurse preceptors.

TABLE 2: Preceptors' perception of support.

\begin{tabular}{|c|c|c|c|}
\hline Item & $N$ & $M$ & SD \\
\hline Nurse educator is supportive of the preceptor role. & 41 & 4.88 & 0.954 \\
\hline Nurse manager is supportive of the preceptor role. & 41 & 4.54 & 1.12 \\
\hline $\begin{array}{l}\text { Professional nurses in the nursing unit are supportive } \\
\text { of the preceptor role. }\end{array}$ & 41 & 4.32 & 1.213 \\
\hline Nursing staff understand goals of the preceptor role. & 41 & 3.95 & 1.264 \\
\hline $\begin{array}{l}\text { Workload is appropriate when functioning as a } \\
\text { preceptor. }\end{array}$ & 41 & 3.93 & 1.523 \\
\hline
\end{tabular}

$N, 41 ; M$, mean; SD, standard deviation.
According to Horton et al. (2012:6) preceptors must be responsible for fewer patients for the first few weeks of the preceptorship. They also suggested that inability to decrease the workload has typically been blamed on the nurse managers. It may be significant that if the workload is not adequate, nurse preceptors will not feel supported and may therefore feel less committed to the preceptor role.

\section{Section D: Nurse preceptors' perceptions of commitment to the preceptor role}

The trained preceptors' perceptions of commitment to the role are presented in Table 3.

Most participants in this study $(90.3 \%$ or $n=37)$ agreed they were inspired to perform their very best in the role of nurse preceptor, whereas $9.7 \%(n=4)$ disagreed. None of the preceptors who disagreed perceived having received sufficient support for their role as nurse preceptor, which could be the reason for not being committed to the preceptor role. According to Martin, Brewer and Barr (2011:1) preceptors shared a desire and commitment to do the best job possible. Hyrkäs and Shoemaker (2007:523) state that commitment to the role of precepting is significantly related to the support that the preceptors receive and the rewards and benefits they perceive.

The results of this study relating to preceptors' perception of the training programme were mostly positive. The participants were proud to have completed the training; they displayed enthusiasm and confirmed that the training programme was aligned with their goals and values. They also perceived the training programme as being adequate in preparing them for the preceptor role. These findings suggest that the participants were satisfied with the preceptor training programme that they attended at UWC.

\section{Ethical considerations Potential benefits and hazards}

The researcher assessed the risks and benefits that might be incurred in this study. No major risks to the participants (for example, physical harm, discomfort, psychological stress) were foreseen by the researcher. Benefits to the research

\begin{tabular}{|c|c|c|c|}
\hline Item & $N$ & $M$ & SD \\
\hline $\begin{array}{l}\text { Deciding to be a preceptor was a definite mistake on } \\
\text { my part. }\end{array}$ & 41 & 5.51 & 1.121 \\
\hline $\begin{array}{l}\text { Being a preceptor really inspires me to perform my } \\
\text { very best. }\end{array}$ & 41 & 5.41 & 0.974 \\
\hline I am proud to tell others that I am a preceptor. & 41 & 5.37 & 0.859 \\
\hline $\begin{array}{l}\text { I am enthusiastic about the preceptor programme } \\
\text { when I talk to my nursing colleagues. }\end{array}$ & 41 & 5.34 & 0.825 \\
\hline I feel very little loyalty to the preceptor programme. & 41 & 5.29 & 1.25 \\
\hline $\begin{array}{l}\text { I find that my values and the values of the preceptor } \\
\text { programme are similar. }\end{array}$ & 41 & 5.27 & 0.895 \\
\hline $\begin{array}{l}\text { My goals are clearly defined by the preceptor training } \\
\text { programme. }\end{array}$ & 41 & 5.2 & 0.872 \\
\hline $\begin{array}{l}\text { I feel I have had adequate preparation for my role as } \\
\text { a preceptor. }\end{array}$ & 41 & 5.02 & 1.107 \\
\hline
\end{tabular}

$N$, 41; M, mean; SD, standard deviation. 
participants included satisfaction that the information they provided could assist in the preceptor training programme evaluation, and giving them an opportunity for introspection.

\section{Recruitment procedures}

Ethical clearance and approval of the proposal (study reference number 12/6/31) was obtained from the Higher Degrees Committee as well as the Senate Committee of UWC. Participation in the research study was voluntary and the participants were aware that they could withdraw from the study at any time.

\section{Informed consent and confidentiality}

On the day of receipt of the questionnaire participants were informed about the aims and objectives of the research study through an information letter. Informed consent was secured prior to the study through a signed consent form. The questionnaires were kept in a locked cupboard to which only the researcher had access. The information collected from the participants was kept confidential.

\section{Trustworthiness}

\section{Reliability}

A pilot study was done to determine whether the instrument was reliable. Cronbach's alpha test was used to determine the reliability of the adapted questionnaire. The questionnaire was piloted, and this revealed that questions were clear and no adaptations were needed. The reliability analysis of the three scales (PPBR, PPS and CPR) yielded alpha coefficients of $0.73,0.76$ and 0.75 respectively, which means that these scales are reliable and that the adapted questionnaire was reliable and acceptable for the study.

\section{Validity}

Content validity of the instrument was ensured through consultation with experts in the nursing field regarding nurse preceptorship, research and statistics. Face validity of the instrument was ensured by conducting a pilot study with two nurse preceptors who had completed the preceptor training programme at UWC. These responses gave the researcher an opportunity to determine whether the instrument was user-friendly and whether the questions asked in the instrument were clear (Polgar \& Thomas 2013:108).

\section{Limitations of this study}

This study was limited to professional nurses who had completed the preceptorship training programme at the School of Nursing, UWC. It would be difficult to generalise the findings to preceptors completing training in other institutions or areas. The nature of preceptor training in other countries is different from the training offered in the Western Cape. Preceptors employed outside of the Western Cape did not form part of this study. The small size of the study population also affected the researcher's ability to generalise findings.

\section{Recommendations}

The results show that preceptors working within clinical units are more committed to their role than those working within education units. It is recommended that interdepartmental negotiation between these units could ensure that those nurse preceptors working in education units be allocated to clinical units within the healthcare services for specific periods of time. This will allow nurse preceptors to have extended contact with student groups, which may influence their CPR.

The workload of the preceptors needs to be revised and managers need to review the task allocation of the trained preceptors. It is essential that in-service training should be offered to all nursing staff to orientate them to the role of the preceptor, so that they can offer support to the nurse preceptor. It is proposed that mainly those professional nurses who show an interest in preceptorship, who have appropriate clinical experiences and who show willingness to the preceptor role, be selected for preceptor training.

UWC's School of Nursing needs to be informed of the nurse preceptors' perceptions of the training programme and its adequacy. This will have an impact on the decision of whether or not the training will be continued. A support network needs to be established for those preceptors who have minimal preceptor experience in the field.

It is recommended that a qualitative study be carried out to explore and describe in-depth experiences of nurse preceptors who have successfully completed the preceptor training programme at the School of Nursing of UWC. Such a study could add value to what is now known about the perceptions of the nurse preceptors, and be used to improve the preceptor training offering.

\section{Conclusion}

This quantitative descriptive correlation study sought to describe the perceptions of nurse preceptors who had successfully completed the preceptor training programme at UWC's School of Nursing. A sample of 41 participants was included in the study from a population of 60 nurse preceptors. An adapted four-part questionnaire was used to collect the data. Data were analysed by using both descriptive and inferential statistics. The research study findings addressed the research objectives and provided answers to the research questions.

Kanter's model of structural determinants of behaviour in organisations supported this study, since preceptors who see themselves as having access to opportunity and support are likely to be committed to their role. The findings of this study indicate that the nurse preceptors experienced the benefits and rewards of and support for preceptorship, and 
are committed to their role. Final analyses were made and the findings were discussed in relation to existing literature and the conceptual framework used for this study.

\section{Acknowledgements}

The School of Nursing's Centre for Teaching and Learning Scholarship (CENTALS) at UWC is hereby acknowledged for the scholarship awarded to the researcher.

\section{Competing interests}

The authors declare that they have no financial or personal relationship(s) that may have inappropriately influenced them in writing this article.

\section{Authors' contributions}

I.S.C. (UWC) was the primary researcher, obtained ethical clearance for the research, performed the literature review, collected data and analysed the data, and was responsible for the final report and writing of the manuscript. J.J. (UWC) provided valuable contributions and guidance through the development of the article. I.S.C. finalised the organisation of the article according to the guidelines provided by Curationis and finalised all corrections accordingly.

\section{References}

Baltimore, J.J., 2004, 'The hospital clinical preceptor: Essential preparation for success', Journal of Continuing Education in Nursing 35(3), 133-140, viewed 09 October 2012, from http://www.countiesmanukau.health.nz/Funded-Services/ PHC-nursing/preceptorship/documents/newsletters_articles/Article_Baltimore.pdf

Bradshaw, C., Butler, M., Cassidy, I., Egan, G., Fahy, A., Mc Namara, M., O'Conner, M., Quillinan, B., Tierney, C. \& Tuohy, D., 2011, 'Competency assessment methods - tool processes: A survey of nurse preceptors in Ireland', Nurse Education in - tool processes: A survey of nurse preceptors in Ireland, Nurse Ed

Brink, H., Van der Walt, C. \& Van Rensburg, G.,2006, Fundamentals of research methodology for health care professionals, 2nd edn, Juta \& Co., Cape Town.

Brown, T., 2010, 'Exploration of relationships among nursing preceptors' demographic variables and perceptions of benefits, rewards, support, and role commitment', Master's thesis, Dept. of Science, Ball State University.

Campbell, S.H. \& Hawkins, J.W., 2007, 'Preceptor rewards: How to say thank you for mentoring the next generation of nurse practitioners', Journal of the American Academy of Nurse Practitioners 19(1), 24-29. http://dx.doi.org/10.1111/j. 1745-7599.2006.00186.x

Carlson, E., Wann-Hansson, C. \& Pilhammar, E., 2009, 'Teaching during clinical practice: Strategies and techniques used by preceptors in nursing education', practice: Strategies and techniques used by preceptors in nursing education',
Nurse Education Today 29(5), 522-526. http://dx.doi.org/10.1016/j. Nurse Education
nedt.2008.11.012

Currie, L \& Watts, C., 2012, Preceptorship and pre-registration nurse education, viewed 11 November 2013, from http://www.williscommission.org.uk/ data/ assets/pdf_file/0011/479936/ Preceptorship_and_pre-registration_nurse education.pdf

Dibert, C. \& Goldenberg, D., 1995, 'Preceptors' perceptions of benefits, rewards, supports and commitment to the preceptor role', Journal of Advanced Nursing 21(6), 1144-1151. http://dx.doi.org/10.1046/j.1365-2648.1995.21061144.x

Dube, A., 2009, The role of the preceptor in selected clinical nursing practice settings in Botswana, University of South Africa, Botswana.

Franklin, N., 2013, 'Clinical supervision in undergraduate nursing students: A review of literature', E-Journal of Business Education and Scholarship of Teaching 7(1),
$34-42$, viewed 12 November 2013, from http://www.ejbest.org/upload/eJBEST_ 34-42, viewed 12 November 2013
Franklin_-_7\%281\%29_2013.pdf
Hallin, K. \& Danielson, E., 2008, 'Being a personal preceptor for nursing students: Registered nurses' experiences before and after introduction of a preceptor model', Journal of Advanced Nursing 65(1) 161-174 http://dx.doi. org/10.1111/j.1365-2648.2008.04855.x

Hautala, K.T., Saylor, C. R. \& O'Leary-Kelley, C., 2007, 'Nurses' perceptions of stress and support in the preceptor role', Journal for Nurses in Staff Development 23(2), 64-70. http://dx.doi.org/10.1097/01.NND.0000266611.78315.08

Horton, C., DePaoli, S., Hertach, M. \& Bower, M., 2012, 'Enhancing the effectiveness of nurse preceptors', Journal for Nurses in Staff Development 28(4), E1-E7, viewed 23 July 2012, from http://www.nursingcenter.com/ Inc/CEArticle?an=00124645-201207000-00014\&Journal_ID=54029\&Issue ID=1400165

Hyrkäs, K. \& Shoemaker, M., 2007, 'Changes in the preceptor role: Re-visiting preceptors' perceptions of benefits, rewards, support and commitment to the role', Journal of Advanced Nursing 60(5), 513-524. http://dx.doi.org/10.1111/ j.1365-2648.2007.04441.x

Kanter, R.M., 1977, Men and Women of the Corporation, Basic Books, New York.

Kaviani, N. \& Stillwell, Y., 2000, 'An evaluative study of clinical preceptorship', Nurse Education Today 20(3), 218-226. http://dx.doi.org/10.1054/nedt.1999.0386

Kupferman, K., 2005, 'Ten ways to help students grow', Nursing 35(4), 56-57, viewed 12 October 2012, from http://www.countiesmanukau.health.nz/ Funded-Services/PHC-nursing/preceptorship/documents/newsletters_articles/ Kupfermann.pdf

Mabuda, B.T., Potgieter, E. \& Alberts, U.U., 2008, 'Student nurses experience during clinical practice in the Limpopo Province', Curationis 31(1), 19-27. http:// dx.doi.org/10.4102/curationis.v31i1.901

Martin, D., Brewer, M. \& Barr, N., 2011, ‘Gradually guiding nursing students through their capstone course: Registered nurse preceptors share their experiences', in D. Martin, M. Brewer \& N. Barr (eds), Nursing research and practice, Hindawi D. Martin, M. Brewer \& N. Barr
Publishing Corporation, Hindawi.

McCarthy, B. \& Murphy, S., 2010, 'Preceptors' experiences of clinically educating and assessing undergraduate nursing students: An Irish context', Journal of Nursing Management 18(2), 234-244. PMid:20465751.

Moran, C., 2011, An investigation of the preceptors' perceptions of benefits, rewards, supports, and commitment to the preceptor role among a sample of nurses, Midwest Nursing Research Society, Aurora.

Moyer, B.A. \& Wittmann-Price, R.A., 2008, Nursing education: Foundations for practice excellence, F.A. Davis, Philadelphia, PA.

Myrick, F. \& Yonge, O., 2004, 'Enhancing critical thinking in the preceptorship experience in nursing education', Journal of Advanced Nursing 45(4), 371-380. http://dx.doi.org/10.1046/j.1365-2648.2003.02920.x

Polgar, S. \& Thomas, S., 2013. Introduction to research in the health sciences, Churchill Livingstone/Elsevier, Edinburgh.

Raines, D., 2012, 'Nurse preceptors' views of precepting undergraduate nursing students', Nursing Education Perspectives 33(2), 76-79. PMid:22616403.

Scott, E., 2010, 'Lessons learned from formal preceptorship programs', Creative Nursing 16(4), 198-199. http://dx.doi.org/10.1891/1078-4535.16.4.198

Smedley, A.M., 2008, 'Becoming and being a preceptor: A phenomenological study', Journal of Continuing Education in Nursing 39(4), 185-191. http:// dx.doi.org/10.3928/00220124-20080401-08

South African Nursing Council, 1985, Regulations relating to the approval of and the minimum requirements for the education and training of a Nurse (General, Psychiatric and Community) and Midwife leading to registration, viewed 10 April 2012, from http://www.sanc.co.za/regulat/

South African Nursing Council, Nursing Act, Act No. 33 of 2005, viewed 12 October 2012, from http://www.denosa.org.za/upload/acts/Nursing_Act.pdf

Staykova, M., Huson, C. \& Pennington, D., 2013, 'Empowering nursing preceptors to mentoring undergraduate senior students in acute care settings', Journal of Professional Nursing 29(5), 32-36. PMid:24075269.

Supino, P. \& Borer, J., 2012, Principles of research methodology: A guide for clinical investigators, Springer, London. http://dx.doi.org/10.1007/978-1-4614-3360-6

Tullis, T. \& Albert, B., 2008, Measuring the user experience: Collecting, analysing, and presenting usability metrics, Morgan Kaufmann Publishers, Burlington, MA

Usher, K., Nolan, C., Reser, P., Owens, J. \& Tollefson, J., 1999, 'An exploration of the preceptor role: preceptors' perceptions of benefits, rewards, support and commitment to the preceptor role', Journal of Advanced Nursing 29(2), 506-514. PMid:10197953.

Yonge, O., Hagler, P., Cox, C. \& Drefs, S., 2008, 'Time to truly acknowledge what nursing preceptors do for students', Journal for Nurses in Staff Development 24(3), 113-116. PMid:18525412.

Zilembo, M. \& Monterosso, L., 2008, 'Towards a conceptual framework for preceptorship in the clinical education of undergraduate nursing students', Contemporary Nurse: A Journal for the Australian Nursing Profession 30(1), 89-94. PMid:19072195. 